\title{
Desarrollo y corrupción
}

\section{Susan RoseAckermann *}

La corrupción extendida es un síntoma de que el Estado está funcionando mal. Los Estados inefectivos pueden retrasar y dirigir erróneamente el desarrollo económico. La ayuda internacional y las organizaciones prestatarias han comenzado a centrarse en el control de la corrupción como parte de un replanteamiento general de su papel en el mundo posterior a la guerra fría. La creación de estructuras institucionales favorables al desarrollo económico es una creciente prioridad.

La corrupción acontece por todo el mundo, pero resulta especialmente preocupante en el caso de los páses pobres. Aquellos que pagan y aquellos que reciben sobornos pueden llegar a expropiar la limitada riqueza de un país, dejando muy poco para los ciudadanos más pobres. Con la corrupción sistémica, incluso los países que tienen una importante cantidad de recursos naturales pueden no lograr desarrollarse en una forma que permita la obtención de beneficios por parte de los ciudadanos normales. Los páses pobres y altamente corruptos se enfrentan a especiales retos incluso cuando están controlados por dirigentes políticos con reformas en mente. La reforma de las instituciones públicas y de las políticas gubernamentales era necesaria, pero la pobreza de un país limita las opciones disponibles.

Dado que la corrupción se equipara normalmente al mal, a menudo su sola existencia es causa de preocupación. Sin embargo, un economista puede llegar a tal conclusión, sólo tras entender el impacto de la corrupción en la eficiencia y en la equidad del sistema económico. Si su impacto es benigno, en ese caso los economistas estarán a favor de una reforma legislativa, dado que existen costes, tanto psicológicos como financieros, derivados de etiquetar como ilegal una práctica que de hecho es funcional. Por tanto, comienzo este trabajo con una visión general de los costes y las causas de la corrupción, tal y como se han manifestado en las pruebas empíricas y en la literatura teórica. Paso después a considerar la diferencia entrela corrupción quese concentra arriba y la corrupción descentralizada que involucra a muchos pagadores y receptores. Con este escenario de fondo, me centro en las opciones políticas existentes para los países en desarrollo cuyos líderes están comprometidos con la reforma y se preguntan qué papel jugará el Banco Mundial en la ayuda a estos esfuerzos.

\section{Costes y causas de la corrupción}

Todos los Estados, tanto los Estados benevolentes como los represivos, controlan la distribución de beneficios valiosos y la imposiciones de costes onerosos. Ladistribución dedichosbeneficios y sus costesseencuentranormalmentebajo el control delos agentes en cuyas manos estáel poder discrecional. Losindividuos privados y las compañías que quieren obtener un trato favorablepueden estar dispuestos a pagar a dichos agentes. Pero ¿quéhay de malo en pagar por aquello que quieres? Esa es, al fin y al cabo, la base del sistema de mercado. El problema surge del hecho de queel receptor del pago es un agente. El agente es responsable frente a un director, cuyos objetivos rara vez coinciden con los del «consumidor pagador». Los burócratas denivel inferior son agentes delos oficiales superiores, los ministros son responsables frente a la coalición de gobierno, los cargos electos son responsables frente al público votante, y los jueces responden frente a las normas legal es. Los pagos son corruptos cuando se realizan de forma ilegal a agentes públicos con vistas a obtener un ben eficio o evitar un coste. Estos pagos no son meras trasnferencias. Afectan al comportamiento tanto de los pagadores como de los receptores de dichos pagos. Las sociedades pueden trazar los límites entre los regalos legales y los pagos ilegales en diferentes puntos, pero a la hora de pensar donde deben trazarse dichos límites, uno debe preguntarse si el pago a los agentes mejora o debilita los objetivos públicos. Un análisis económico de la corrupción busca determinar las consecuencias eficientes de la adquisición de beneficios por parte de los agentes por medio de sobornos. 
Recientes estudios comparativos indican que la existencia de instituciones gubernamentales y legales fuertes, y los bajos niveles de corrupción, tienen efectos beneficiosos en el crecimiento económico entre otras variables ${ }^{1}$. D ado que los índices de corrupción se corresponden mucho con otras medidas de eficiencia burocrática, tales como el nivel de burocratizados y la calidad de los jueces, estos estudios no logran distinguir el efecto marginal que puede tener cualquiera de estas medidas si mantenemos las demás constantes. Los datos resultan consistentes con la afirmación de que la corrupción es una función del nivel de burocratización, pero este nivel es en sí mismo en parte una función de la prevalencia de la corrupción. La corrupción es síntoma de otros problemas subyacentes más que una variable independiente ${ }^{2}$. N 0 hay región alguna que haya conseguido escapar del impacto negativo de la corrupción. Por ejemplo, un estudio reciente reveló que la inversión extranjera directa (IED) se asocia negativamente con altos índices de corrupción. No había nada especial acerca de los países del este asiático - también para ellos la corrupción desincentivaba el IED (W El, 1997)- . Un segundo estudio reveló que las políticas industriales pueden verse debilitadas por la corrupción. D e nuevo, los países asiáticos no eran una excepción a esto. (ADES y DI T ELLA, 1995).

Para ir más allá de estos hallazgos macroeconómicos, necesitamos aislar los aspectos estructurales que crean incentivos corruptos. Seis amplias categorías que confluyen logran capturar las situaciones que generan incentivos corruptos.

- Se puede acusar al gobierno de distribuir un beneficio escaso a muchos individuos y empresas, utilizando criterios legales distintos a la voluntad de pagar. Lossobornosdejan el mercado libre.

- Los funcionarios del sector público pueden tener pocos incentivos para realizar su trabajo, teniendo en cuenta que se les paga conforme a unas escalas y teniendo en cuenta el nivel de dirección interna. Los sobornos sirven de bonus que incentivan.

- Las empresas privadas y los individuos tratan de reducir los costes que se le han impuesto por el gobierno por medio de impuestos, pagos de aduana y regulaciones. Los sobornos disminuyen los costes para aquellos que los pagan.

- A menudo los gobiernos transfieren grandes beneficios financieros a empresas privadas por medio de contratos de procura, privatizacionesy la entrega de concesiones. L os sobornosafectan al nivel de rentas de monopolio y a su división entre inversores privados y empleados públicos.

- Los sobornos pueden sustituir formas legales de influencia política. El soborno de los políticos compra la influencia, y el soborno por parte de los políticos compra votos.

- Losjueces tienen el poder de imponer costes y transferir recursos entre litigantes. Los sobornos pueden soslayar lasnormasle gales.

\section{Los sobornos como pagos que igualan la oferta y la demanda}

A menudo los gobiernos proporcionan bienes y servicios de forma gratuita 0 a precios muy por debajo de los precios de mercado. A veces incluso existen precios duales. En China, por ejemplo, al gunos bienes de los producidos se venden a precios de subsidiados por el Estado y en el mercado libre. En 1989 el precio de mercado del carbón era del 674 por ciento del precio subsidiado. No resulta, por tanto, sorprendente que los pagos para obtener mercancias a precios del Estado fueran bastante comunes ${ }^{3}$. Los índices de cambio de divisas múltiples y las cuotas de importación suelen ser fuentes frecuentes de pagos. Cuando la concesión del crédito y el índice de interés están controlados por el Estado, se pueden llegar a pagar sobornos para acceder a los mismos ${ }^{4}$.

Los incentivos para realizar pagos son suficientemente claros en estos casos, pero ¿cuáles son las consecuencias en cuanto a la efectividad? Supongamos, primero, que al que soborna se le permite recibir un escaso beneficio pero se le requiere que pague por él. Si el mercado corrupto funciona de forma eficiente, el servicio se proporcionará a los solicitantes que tengan la mayor voluntad para pagar por él. Tomemos, sin embargo, en consideración las formas en que los resultados ineficientes o injustos pueden surgir. En primer lugar, los objetivos de los programas diseñados para el beneficio de los más necesitados o los mejor cualificados se verá debilitado si los servicios sólo se prestan a aquellos con los más altos niveles de voluntad de pagar ${ }^{5}$. En segundo lugar, los mercados corruptos son menos abiertos que los mercados competitivos (CARTIER-Bresson, 1995; Gam BetTA, 1993; RoseACKERMAN, 1978). La ilegalidad de los sobornos induce a los participantes en ella a gastar recursos en mantener dicha transacción secreta. La información sobre los precios de los sobornos no se hará pública muy bien, y los precios serán pegadizos. Algunos participantes potenciales pueden negarse a entrar en ese mercado por sus escrúpulos morales o por su miedo al castigo, y los empleados públicos pueden limitar sus negociaciones a personas que estén dentro de su ámbito y a amigos en los que confían. M ás aún, un sistema corrupto puede no ser sólo menos competitivo sino más inseguro que un mercado legal ${ }^{6}$.

En la práctica, muchos empleados públicos pueden ejercer un poder monopolístico al determinar la cuantía de los servicios que proporcionan. El empleado público, al igual que un monopolista privado, puede intencionadamente decidir que el servicio que se preste esté por debajo del que se exige oficialmente, para incre mentar las rentas económicas disponibles para la división. Inversamente, bajo condiciones diferentes el empleado corrupto pue de querer aumentar el nivel de servicios que va a proporcionar si el gobierno ha fijado dicho provisión por debajo del nivel de mo- 
nopolio. En otras situaciones, el servicio no es escaso, pero, al igual que un pasaporte, o un carné de conducir, o una pensión de vejez, sólo está disponible para aquellos «cualificados» para ello. Los empleados, sin embargo, pueden tener suficiente poder de monopolio para crear escasez, bien retrasando la aprobación de dichos servicios o manteniéndose paralizados salvo que se les paguen sobornos (PAUL, 1995).

Por último, a menudo los sobornos se pagan para permitir que los no cualificados para ello obtengan el beneficio. SHLEIFER y V ISH NY (1993, p. 601) denominan a esto «corrupción con robo». Los estudiantes pagan para alterar los resultados de los tests de su admisiones universitarias; los pacientes pagan a los médicos para que declaren que cumplen los requisitos para pagos para discapacitados. Las compañías que no tienen derecho a la obtención de crédito pueden obtener préstamos. Los no cualificados a menudo tienen la mayor voluntad de pagar, ya que no tienen forma legal de obtener el servicio.

\section{Los sobornos como pagos que incentivan a los burócratas}

Los sobornos pueden ser pagos queincentivan la realización de un buen servicio. Las empresasy losindividuos pueden pagar para evitar retrasos. En algunos modelos económicos tienen deseables propiedades deincentivación. Por ejemplo, los pagoshechosa gestores de servicios pueden ser eficientes ya que dan a los empleados públicos incentivos para que trabajen deprisa y a favor de todos aquellos que aprecian mucho su tiempo (LUI, 1985). La corrupción de los recaudadores de impuestos puede ser eficiente siempre que el gobierno pueda imponer una limitación a los ingresos vinculante con carácter general ${ }^{7}$. Pero la tolerancia de la corrupción rutinaria de gestores de servicios de línea y los que recaudan impuestos es extremadamente problemática. En primer lugar, losmodelos asumen quelos empleadossólo tienen un poder discrecional limitado. Por ejemplo, los recaudadores de impuestos «descubren» las responsabilidades fiscales de los ciudadanos y las empresas. En realidad, pueden «crear» de forma creativa la responsabilidad fiscal como un mecanismo de extracción de sobornos, produciendo así un patrón arbitrario e injusto de pagos. En segundo lugar, existen alternativas que evitan los costes de los sistemas de pago ilegales. El acceso a los servicios puede gestionarse por medio de importes diferenciales. Puede ocurrir que se permita a las oficinas de recaudación de ingresos retener una porción de los impuestosque recaudan. En tercer lugar, las empresas pagan sobornos para obtener la certeza, pero los pagos efectuados para incrementar la certeza para las empresas individual es pueden resultar en una gran variedad de condiciones en las distintas empresas (ROSE-ACKERM AN y StONe, 1996) 8 .
En resumen, los sobornos actúan como pagos que incentivan a los empleados públicos. U na política de tolerancia activa, especialmente por parte de donantes externos tales como el Banco M undial, puede muy posiblemente destruir las perspectivas de reforma a largo plazo. Los pagos que se ven con carácter general como aceptables deberían legalizarse, pero no todos los mecanismos de «nncentivos de pago» mejoraran la eficiencia burocrática. Puede, en cambio, favorecer los esfuerzos ineficientes para maximizar las recompensas financieras.

\section{Los sobornos reducen los costes}

Losgobiernosimponen regulaciones, la recaudación deimpuestosy la ejecución de las leyes penales. Los individuosy las empresas pueden pagar paraliberarsedel pago deestoscostes. Pueden ponerse deacuerdo con los recaudadores deimpuestosy losagentesde aduana para reducir las sumas recaudadas. El impacto económico delos sobornos pagados para evitar las regulaciones, suprimir las leyes penales, y reducir losimpuestos, depende de la eficiencia de los programas subyacentes que están sometidos a distorsiones corruptas. Dadala existencia deun marco legal ineficiente, lospagos para evitar las regulacionesy losimpuestos pueden incrementar dicha eficiencia 9 . Estadefensa delos pagos estácomúnmenteapoyadapor losinversorestanto nacional es como extranjerosen el mundo desarrollado. Se trata deuna justificación pragmática que surge dela frustración deéstos con su orden legal existente. Trata dejustificar la corrupción llevada a cabo para obtener beneficiosquees una de las que no están legalmente permitidas.

Pero zacaso los individuosy las empresas sólo vienen obligados a obedecer aquellas leyes que ellos juzguen como eficientes y justas? En el mundo industrial, la respuesta de la industria a las reglas que encuentra duras no suele ser la de sobornar a los empleados públicos o recurrir a criminales para evadir la ley. En cambio, las empresas trabajan para cambiar las leyes, para hacer contribuciones a campañas legales, agencias públicas de grupos de presión, e iniciar procesos judiciales que ponen en cuestión las leyes y regulaciones existentes. Uno puede quejarse acerca de la importancia de la riqueza y de las grandes corporaciones en la vida política, las actividades de losgrupos de presión bien documentadosy las contribuciones a campañas son al menos superiores a los sobornos secretos llevados a cabo para mantener las instituciones democráticas. Algunas de las mismas empresas que se involucran en actividades políticales legales en su país se sienten menos constreñidas a la hora de violar las leyes en las economías desarrolladasy en transición. D esdequeEE.UU . prohíbelossobornospagadosen el extranjero para real izar negocios, las empresas americanas seenfrentan a un constreñimiento legal doméstico ${ }^{10}$. Pero la importancia que se percibe de dicho constreñimiento sugiere que las mul- 
tinacionales generalmente no sienten la obligación de obedecer la ley en los países desarrollados en los que operan.

D esafortunadamente, los inversores pagarán sobornos no sólo para evitar las reglasy losimpuestosineficientes. Q uerrán reducir el impacto detodas las cargas impuestas por el Estado, estén o no justificadas. Parece extraño tolerar las opiniones mantenidas por las empresas de negocios de queun pago bien hecho está justificado porqueaumenta susbeneficios. Tal tipo de actitud puede provocar un daño serio a aquellas naciones queluchan para construir Estadosviables. EstosEstadosnecesitan desarrollar institucionespúblicas que traduzcan las necesidades populares en leyes, que establezcan un compromiso creíble con la ejecución de estasleyes, y que proporcionen recursos legales para aquellos que consideren que han sido dañados. Si, en cambio, los inversores y los ciudadanos ordinarios deciden por su cuenta qué leyes son legítimas, el intento de crear instituciones estatal es fracasará. La reforma de las leyes puede servir para apoyar la legitimidad estatal si el resultado final es un conjunto de constreñimientos legales que se basan en objetivos públicos generales, tales como la eficiencia económica y la equidad. Los esfuerzos internacionales por reducir la aceptación de sobornos y aumentar los costes puede ayudar a cambiar tales comportamientos, pero el papel de las políticas delas empresasindividual es y los códigos de conducta no debería infravalorarse.

\section{Sobornos para obtener contratos importantes, concesiones, y empresas privatizadas}

Los pagos corruptos para ganar contratos importantes y concesiones y para privatizar las empresas son generalmente la forma de preservar los grandes negocios a los empleados públicos de alto nivel. ¿Existe algo distintivo de tal tipo de corrupción más que el tamaño de los negocios que se llevan a cabo? Parecen ser análogos a los casos en los que el gobierno paga escasos beneficios. ¿A caso la escala del negocio corrupto y la implicación de los empleados públicos de alto nivel cambia algo?

Una diferencia estriba en que los líderes quedan apartados de toda posible condena y por tanto se les puede constreñir menos en sus demandas corruptas que a los empleados de inferior nivel. Una segunda diferencia es que aquellos que obtienen beneficios por medio del pago de sobornos a empleados de nivel inferior rara vez se piensa que se comportan de forma ineficiente una vez obtenido el beneficio. En contraste con esto, para los grandes negocios a menudo se da el argumento contrario. ¿Pero existe algo especialmente reseñable respecto de esto? Para aislar estos distintivos aspectos, consideren una concesión para la obtención de troncos de madera obtenida de forma corrupta por parte de una compañía por encima de las altas pujas de sus competidores. Si la corrupción no restringe la entrada y si el empleado no puede afectar al tamaño de la concesión, aquel que pague un soborno superior es la empresa que valora más el beneficio. Las pérdidas son los impuestos de más que deben recaudarse y los beneficios perdidos de los programas públicos que no se lleven a cabo. El pago puede ser «sólo» una transferencia, pero es dañino para los esfuerzos llevados a cabo por reducir la pobreza y utilizar el crecimiento para mejorar el bienestar de los ciudadanos ordinarios.

Ahora, consideren la empresa que ha obtenido una concesión de madera segura y a largo plazo a un precio de ganga incluso cuando a ello hay que añadir el soborno. Si opera en el mercado internacional, sus subsiguientes acciones deberían depender del mercado de la madera. Busca maximizar los beneficios, y el pago de la concesión es un coste hundido. Esta defensa de la falta de impacto en el comportamiento de la empresa es demasiado simple para reflejar la realidad. Los términos operativos son segura y a largo plazo. La corrupción introduce incertidumbres en el ambiente económico que pueden dar a la empresa una orientación ineficiente a corto plazo ${ }^{11}$. H ay dos razones para esto. En primer lugar, el concedente puede temer que aquellos en el poder sean vulnerables a ser derrocados debido a su corrupción. Un nuevo régimen puede no respetar los compromisos del viejo régimen. En segundo lugar, incluso si el actual régimen se mantiene en el poder, el ganador puede temer la imposición de demandas arbitrarias una vez que se hundan las inversiones. Puede que se permita a los competidores entrar en el mercado, o se puede anular el contrato por razones de política o de avaricia ${ }^{12}$. D e esta forma, la empresa corrupta puede talar árboles más deprisa de lo que podría hacerlo en países menos corruptos. Puede ser reticente a invertir en capital inmovilizado que podría ser difícil sacar del país.

En algunos países el al to nivel de corrupción sistémica coexiste con un fuerte crecimiento. Se trata de Estados, sobre todo en Asia, que han conseguido crear ambientes económicos relativamente seguros, de tal forma que los negocios apoyados por el Estado respresentan compromisos crébles a largo plazo (CAM POS y RoOT, 1996). Incluso en esos países, sin embargo, la corrupción no es de hecho beneficiosa (W El, 1997). Además de los costes de distribución, la corrupción distorsiona las elecciones de distribución. Esto resulta especialmente obvio durante los periodos de descenso económico que sacan a la luz las relaciones corruptas. Aquellos que se beneficiaron de la corrupción y el patronazgo en el pasado tratan de aferrarse a su ventaja incluso si resulta ineficiente para la sociedad. Consideren, por ejemplo, la habilidad de $\mathrm{H}$ anbo Steel en Corea para obtener préstamos bancarios pese a la falta de garantía crediticia (Far Eastern Economic Review, 
20 de febrero 1997). De forma similar, el envejecimiento de un líder autoritario puede intensificar la búsqueda de rentas por su familia y asociados próximos que a su vez distorsiona las decisiones de inversión. En Indonesia aquellas personas cercanas al pre sidente parecen tratar de guardar con llave las ganancias para el futuro. Las pérdidas que supone para la nación incluyen tanto la pérdida potencial de ingresos fiscales como la posible ineficiencia de algunos proyectos de inversión.

\section{Sobornos para comprar la influencia política y los votos}

La democracia da a los ciudadanos un papel a la hora de determinar a sus líderes políticos. Los empleados públicos corruptos elegidos pueden ser echados del cargo. Pero la democraciano esnecesariamente una cura para la corrupción. En algunos sistemas los políticos corruptos coexisten con las formas democráticas, aunque los ciudadanos están al tanto de esta práctica. Los pagos corruptos se utilizan, en parte, para financiar a los partidos políticos y para las campañas electorales. Financian actividades electorales en general, y en al gunos países la compra a la vista devotos por partede los políticos, aunque ilegal, sucede abiertamente.

Las modernas campañas políticas exigen que haya más recursos que en las viejas campañas electorales. D e esta forma, existe una demanda de mayor financiación para los candidatos y los partidos políticos. A falta de financiación pública, la fuente más conveniente de dinero está en los intereses de los negocios que se pueden beneficiar o verse perjudicados por las decisiones políticas. Incluso si las contribuciones de los negocios se pueden hacer de forma legal, tanto las empresas como los políticos pueden preferir mantener los pagos en secreto si se ve implicado un quid pro quo. Un sistema ilegal de pagos il egales puede debilitar los esfuerzos para reformar la financiación de las campañas políticas. Los estudios de los sistemas políticos en Francia e Italia demuestran cómo los modernos partidos políticos se han pasado a estar dominados por «políticos de negocios» (M ÉnY, 1996; D ELLA POR$T A, 1996)$. El testimonio de los operativos políticos italianos en las recientes investigaciones de «M anos Limpias» revela cómo las prácticas corruptas pueden estar enraizadas en sistemas democráticos (D ElLA PORTA, 1996). En Japón, el Primer Ministro Tanaka Kakuei desarrolló un sistema bajo el que los negocios se asignaban a candidatos para financiar y votar (REED, 1996). La experiencia en EEUU sugiere que incluso las contribuciones le gales a compañas electorales pueden ejercer influencia, pero al menos en tales casos las donaciones son públicas y pueden ser evaluadas por los votantes.
En Italia los «jefes» políticos estaban preocupados con movilizar el voto. Esto podía hacerse no sólo mediante fondos de la campaña sino tambien por medio de la movilización de recursos estatales, trabajos de patronazgo, y otros tipos de favores del gobierno para crear redes de obligación (D ELLA PORTA, 1996). LOS políticos acusados de acumular tesoros de campañas ilegales de guerra en la República de Corea y Japón, justificaron sus acciones por referencia al coste de las campañas en aquellos páses en los que los votantes esperan obtener beneficios personales de los candidatos (PARK, 1995; ReED, 1996). En algunos países la compra de votos es bastante abierta. La provisión de pagos directos a los votantes tiene una larga historia que nos Ileva al siglo XIX en Inglaterra y EE.UU. Las reformas han limitado tales pagos en la mayor parte de los países industrializados, pero siguen siendo un aspecto de la política electoral en otros páses. Por ejemplo, la reciente elección en Tailandia llevada a cabo por una continua práctica de pequeños pagos a los votantes (Far Eastern Economic Review, 28 de noviembre de 1996; para más información sobre Tailandia, ver Phonsgpaicht y Piriyarangsgan, 1994).

En otros países los empleados del gobierno compran votos de los legisladores. Se dispone de fondos presupuestarios especiales parael ejecutivo con poco responsabilidad quefavorecen esta práctica en un número de países, especial mente en Latinoamérica. Cuando el Presidente brasileño Collor fue sometido a un proceso dedestitución frenteal Congreso, los observadores se preocuparon de que los aliados buscaran sobornar a miembros para obtener un veredicto favorable (GEDDES y RIBEIRO N ETO, 1992).

Los conflictos de intereses a los que se enfrentan tanto los políticos como los burócratas son un problema no suficientemente apreciado en muchas economías en transición y en desarrollo. En muchos países pocas leyes regulan las actividades de negocio privado de los empleados públicos, dejándoles la vía abierta para acusaciones de favoritismo. Las leyes de financiación de campañas en muchos países son similarmentepermisivas, aunqueen algunoscasos las reglas son tan sumamente restrictivas que requieren prácticamente transferencias no recogidas para poder financiar dichas campañas. Los recientes escándalosen Francia, Japón, la República deC orea, Italia y EE.UU. ponen de manifiesto la importancia de reglas claras quedirijan la solicitud de dinero privado y la previsión de suficientes recursos legales de financiación.

\section{Sobornos para comprar decisiones judiciales}

Los jueces tienen el poder de afectar a la distribución de riqueza a través de sus decisiones. De esta forma, al igual que un empleado público con similar poder, se enfrentan a incentivos 
corruptos. En algunos países se considera que los jueces son bastante corruptos. Los incentivos corruptos son mayores cuando a los jueces se les paga poco y tienen sobrecarga de trabajo y están pobremente equipados y con poco personal en sus oficinas. Incluso, si los jueces no son en si mismos corruptos, los empleados a cargo de asignar los casos y asesorar a los jueces pueden exigir o aceptar sobornos. En al gunos países latinoamericanos, por ejemplo, la falta de tarifas de tribunales formales genera incentivos para los empleados de los tribunales y jueces para cobrar tarifas no autorizadas. (BUSCAGLIA, 1995).

Los pagos pueden ser una fórmula que hace que los jueces resuelvan con mayor prontitud. Un estudio reveló que los retrasos y bloqueos en Latinoamérica se incrementaron de forma dramática entre 1973 y 1993 (BusCAGLIA, 1995), elevándose, así, los incentivos para pagar sobornos. Los sobornos también pueden influenciar las decisiones a nuestro favor. 0 casionalmente, se han denunciado casos en los que los partidos enfrentados se enfrentan en el pago de sobornos, para ver quién paga más ${ }^{13}$.

Cuando se contempla al poder judicial como corrupto, las incertidumbresseintroducen en el climanegocial. La ley en los libros puede no significar mucho, y aquellos con disputas tratan de evitar traerlas ante los tribunales salvo que estén seguros de que van a ser los que paguen los sobornos más altos. Los individuos evitan acudir al sistemajudicial contratando árbitros privados y utilizando otros métodos, tales como la protección que proporciona el crimen organizado. Un estudio del poder judicial en Latinoamé rica reveló quela mayor parte delos hombres de negocios tratan de evitar utilizar lostribunales para resolver sus disputas. (BUSCAG LIA, 1995). En Europa O riental y en Rusia los asesinatos de los hombres de negocios y de los banqueros son bastante comunes. M uchos parecen asesinatos similares a ejecuciones que son parte del brutal sistema privado de «resolución de disputas» ${ }^{14}$.

Tabla 1.

\section{Tipos de gobiernos corruptos}

\begin{tabular}{|l|l|l|}
\hline \multicolumn{1}{|c|}{ Receptores de sobornos } & Muchos sobornadores & Pocos sobornadores \\
\hline $\begin{array}{l}\text { Concentrados en los niveles } \\
\text { superiores }\end{array}$ & $\begin{array}{l}\text { Cleptocracia (a) puro Estado extorsiona- } \\
\text { dor o (b) Estado débil }\end{array}$ & Monopolio bilateral \\
\hline $\begin{array}{l}\text { Múltiples receptores en los niveles } \\
\text { inferiores del gobierno }\end{array}$ & $\begin{array}{l}\text { Sobornos competitivos } \\
\text { con la posibilidad de espirales }\end{array}$ & Estado dominado por la mafia \\
\hline
\end{tabular}

\section{La corrupción y la organización del gobierno}

El nivel de corrupción depende no sólo de la existencia de rentas económicas sino de la estructura política. Una organización externa, como el Banco M undial, puedejugar un papel constructivo sólo bajo ciertas condiciones político-economicas. Las cleptocracias, en las que la corrupción se organiza a la cabeza del gobierno, deben distinguirse de los Estados en los que la corrupción es la provincia de un gran número de empleados públicos. El otro lado del «mercado» de sobornos debe también especificarse. ¿Existe un número pequeño de actores privados de corrupción principal, o es el pago de los sobornos descentralizado? Juntando estas dos dimensiones se dan cuatro categorías estilizadas: cleptocracia, sobornos competitivos, monopolio bilateral, el extremo de un Estado débil dominado por las mafias.

En una pura cleptocracia el jefe del gobierno puede organizar el sistema político para que maximice las posibilidades de extracción de renta y puede redistribuir esas rentas para uso personal. En el primer caso, el jefe del gobierno se enfrenta a un gran número de potenciales pagadores de sobornos. Uno puede suponer que tal tipo de líder actuará como un monopolista privado, 10 queM ancur O LSON (1993) Ilama «bandido estacionario», Iuchando por la eficiencia productiva pero restringiendo la tendencia de la economía a maximizar los beneficios (FIN Daly, 1991). Sin embargo, en los modelos económicos de monopolio existe un sistema estable de derechos de propiedad y mercado. Los cleptócratas pueden no enfrentarse a tales restricciones. Pueden expropiar la propiedad de otros y extraer la riqueza de los ciudadanos privados por medio de amenazas de violencia. Si los cleptócratas tie- 
nen una propiedad segura, pueden evitar tal comportamiento de explotación y extorsión. Sin embargo, la extracción de rentas con una única intención puede en sí misma aumentar la incertidumbre de la propiedad del gobernante.

M ás aún, la mayor parte de los cleptócratas no son muy poderosos. Su objetivo es la maximización de la riqueza personal, pero lasherramientasa su disposición son imperfectas. Pueden tener un funcionariado débil y desleal, una basepobre derecursos, y un vago y confuso marco legal. Tales gobernantes lo más probable es que favorezcan un Estado excesivamente grande que maximice las posibilidades corruptas. Prefieren evitar desgastes por parte de los subordinados, pero pueden ser incapaces de prevenir y evitar que se dobleguen y acepten sobornos (C O OLID GE y ROSE-ACKERM AN, 1997). Los cleptocrátas fuertes dirigen Estados brutales pero eficientes; los débiles dirigen Estados intrusivos eineficientes en los que al gunas de las ineficiencias son parte del esfuerzo por extraer sobornos de la población y de la comunidad de negocios.

En el segundo caso, un gobernante corrupto se enfrenta a un único principal oponente al otro lado de la mesa. En esta situación, similar a un monopolio bilateral, las posibilidades de extracción de renta se comparten entre el sobornador y el gobernante. Sus relativas fuerzas determinarán la forma en la que las ganancias se compartan y el tamaño de la tarta a compartir. Si al gunas de las rentas pueden crearse sólo con la ayuda del Estado, pero el Estado teme perder todas las ganancias frente a su adversario, no actuará. De forma similar, el líder puede amenazar con expropiar la propiedad y el antagonista puede amenazar con implicarse en violencia.

La mafia es un grupo criminal organizado que proporciona servicios de protección que sustituyen a los que proporciona el Estado en las sociedades normales (G AM BETTA, 1993). En al gunos casos bilaterales el Estado y la mafia comparten el negocio de protección y a menudo se superponen en los miembros que los componen. Un líder corrupto poderoso en estecontexto extorsiona una parte de las ganancias de la mafia. D e forma alternativa, al gunos Estados dependen altamente de pocas empresas de negocios que extraen minerales o producen productos agrícolas. Tales empresas pueden formar una alianza con los líderes del país para compartir la riqueza. Si la empresa ha invertido en un capital fijo o si el producto que produce es una materia prima disponible sólo en al gunas partes de la tierra, los líderes del país están en una posición fuerte. En contraste con esto, si la empresa produce un producto agrícola que puedeir a otro sitio fácilmente, o si la materia prima está disponible para la empresa en diferentes lugares, tiene una ventaja para negociar y puede exigir que el país proporcioneinfraestructura, garantías de paz laboral eimpuestos bajos. Poca corrupción abierta puede observarse en tales regímenes, pero el daño que se puede ocasionar a los ciudadanos ordinarios es sin embargo grave. El país se convierte en un apéndice del gran inversor. Las pérdidas incluyen tanto los costes de distribución como los de eficiencia. El Estado pierde la capacidad de explotar los beneficios de la actividad económica, y la economía es ineficiente, dado que sólo laspolíticas quese defienden por un grupo menor sellevan a cabo. Algunos Estados que crecen rápidamente, especialmente en Asia, pueden encajar en esta categoría, pero su éxito económico parece debilitar este argumento. El interés mutuo entre los gobernantes y los grandes inversores ha resultado en una pacífica alianza entre negocios-Estado que ha evitado las peores patologías del caso del monopolio bilateral (CAm Pos y Ro0т, 1996). Sin embargo, pese a todo ello, si el Estado resulta ser incapaz o no está dispuesto a extenderse más allá de un grupo reducido de inversores a los que favorece, los costes a largo plazo puede ser muy altos, al perder la economía la flexiblidad para responder de manera eficiente a las condiciones cambiantes.

La tercera variante es una con un Estado débil y desorganizado en el que los empleados públicos se involucran en los sobornos por libre. Estos empleados se enfrentan a un monopolio de poder en el sector privado. Al igual que en el caso del monopolio bilateral, el monopolista puede ser una mafia doméstica 0 una gran corporación. En cualquiera de los dos casos, el sector privado domina al Estado, comprando la cooperación de los empleados de bajo nivel, pero no es capaz de organizar el Estado en un cuerpo unitario. La desorganización y la debilidad del Estado reducen la capacidad del grupo privado para obtener los beneficios que desea. Llegar a un acuerdo con un empleado no desanimará a otro de pasar adelante.

El cuarto caso es aquel en el que muchos empleados públicos se enfrentan a gran cantidad de gente corriente y de negocios. Un problema fundamental con tal situación es la posibilidad de una espiral ascendente de corrupción. La corrupción de algunos puede animar a otros empleados a aceptar sobornos hasta que todos, menos los moralistas no reconstruidos, sean corruptos. Bajo condiciones admisibles, existen dos posibles equilibrios - uno con un alto nivel de corrupción y otro con muy poca corrupción-. El problema de los reformadores es cómo mover a un país de un equilibrio a otro (ver AndVIG y M OENE, 1990; BesLey y M CLAREN, 1993; CADOT, 1987).

Una forma de salir de la corrupción es equiparar la pena esperada al nivel de corrupción. El equilibrio con un alto nivel de corrupción sucede porque la red de recompensas de corrupción aumenta al incrementarse la incidencia de corrupción. En contraste supongan que la probabilidad de ser descubierto aumenta a medida que lo hace el tamaño y la incidencia de los sobornos. Entonces ya no será cierto que los sobornos más altos y un alto nivel de sobornos vayan unidos. Pocas personas pueden pagar sobornos, pero los que lo hacen pagarán sobornos de gran cantidad de dinero. Los esfuerzos de ejecución de la ley habrán aumentado el tamaño y habrán reducido la incidencia de los pagos.

Algunos países experimentan la corrupción tanto en los niveles superiores como en los niveles inferiores del gobierno. ¿D ónde deberían entonces concentrarselos esfuerzos de reformar?Algunos 
analistas son relativamente sanguinarios respecto a la cl eptocracia, argumentando queel problema más serio es la corrupción descentralizada, bajo la que empleadosse dedican a pescar «por encima de lo permitido» en su búsqueda derentas(SH LEIFER y VISH NY, 1993; O LSON, 1993; ROD RIK, 1994). «Pescar por encima de lo permitido» puede ser el resultado de una estructura de gobierno descentralizada 0 una jerarquía mal organizada con la discreción ejercida por los que están abajo. D esde esta óptica, la corrupción a la cabeza se diseñará para maximizar el monopolio delas rentasy conducirá a restricciones en la provisión de servicios ineficiente, pero no tendrá ningun impacto sobre la eficiencia productiva.

Una implicación política de este análisis es que deberían dedicarseespeciales esfuerzos para reducir la corrupción en los bajosniveles. Ésta es una conclusión problemática. El modelo asume un nivel fijo de rentas en el sector privado (la piscina común) que los empleados públicos tratan de extraer. En realidad, los empleados pueden disponer de poder para expandir dicha piscina, y los empleados de más alto nivel generalmentetendrán el poder para aumentar el alcance del Estado más que los empleados de los niveles inferiores 0 aquellos en los gobiernos estatal es y locales. Pero, uno podría argumentar que el cleptócrata todopoderoso y seguro evitará tales políticas ineficientes. Sin embargo, la corrupción en sí misma puede ser una fuente de inseguridad. Esta inseguridad da a los gobernantes una perspectiva a corto plazo que les anima a realizar robos adicionales, haciéndolos incluso más inseguros. Además, pocos son todopoderosos. Susúnicas herramientas son ineficientes y confiscatorias. De esta forma, los casos en los que uno puede estar seguro de que el cleptócrata se comportará como un monopolista privado parecen ser limitados.

El Banco M undial necesita adoptar decisiones difíciles sobre dónde realizar préstamos y dónde apoyar la reforma política. De bería concentrarse en aquellos países en los que los máximos líderes están razonablemente comprometidos con un gobierno limpio a la cabeza al igual queen las cotas inferiores. Los países dominadospor líderes cleptocráticos y los Estados débiles dominados por extranjeros corruptos son candidatos pobres para dicho apoyo. Por supuesto, la mayor parte de los países pobres están algo en el centro. La corrupción puede estar bien enraizada, pero algunos empleados están genuinamente comprometidos con la reforma. En tales casos, el Banco debe adoptar un punto de vista comprensivo. No sirve al objetivo de crecimiento económico para ayudar al reformador a limpiar los sistemas fiscales y de aduana, si el líder utiliza estos procedimientos para su propio beneficio personal.

\section{Programas de reforma}

$\mathrm{H}$ abiendo aislado los incentivos económicos para la corrupción, y habiendo puesto el problema en un contexto político gene- ral, voy ahora a analizar los pasos que puede dar un gobierno interesado en la reforma para reducir la corrupción. M uchas de estas reformas pueden ser apoyadas por proyectosy préstamos del Banco M undial, pero sólo si loslíderes políticos de un país están dispuestos a cargar con los costes del cambio. Las posibilidades de reforma dependen de la capacidad del Estado y, sobre todo, de los niveles de pobreza, pero la gama de opciones puede especificarse. Además de los esfuerzos para cambiar lasactitudes socialesy las expectativas, las políticas anticorrupción pueden reducir las oportunidades de corrupción que se encuentran bajo el control de los empleados públicos, por un lado, y aumentar los beneficios de ser honesto y los costes de ser corrupto, por otro lado. Los incentivos parala corrupción se ven influenciados por los siguientes factores:

- El nivel de beneficios y costes que están bajo el control discrecional de los empleados.

- Las leyes formales en materia de corrupción, sobornos, conflictos de intereses, financiación de campañas, y la credibilidad de la ejecución de las leyes.

- Las condiciónes de empleo del funcionariado y los sistemas de incentivos dentro del funcionariado.

- El grado de auditoría y dirección dentro del gobierno.

- La habilidad de los ciudadanos para aprender acerca de las actividades del gobierno y presentar reclamaciones.

- El nivel de libertad de los medios de comunicación, y la libertad de los individuos para formar organizaciones no-gubernamentales.

- El nivel de oposición política activa.

M e centro en cuatro grandes categorías: reducciones en el poder discrecional de los empleados del gobierno, ejecución de las leyes anticorrupción, reforma del funcionariado, y una responsabilidad mayor del gobierno frente a los ciudadanos.

\section{Reduciendo los incentivos por pagos}

Las reformas más básicas son aquellas que reducen el nivel de beneficios bajo el control de los empleados públicos. Una estrategia de reforma debe hacer esto, sin embargo, sin eliminar los programas que tienen importantes justificaciones públicas, y sin simplemente cambiar los beneficios al sector privado, donde aparecerán como beneficios monopolistas. Dado que tales reformas van paralelas al desarrollo de las prioridades del Banco M undial, el personal del Banco puede ser especialmente útil a la hora de proporcionar consejo técnico en esta área.

La opción más evidente es simplemente eliminar las leyes y programas que están permeados con la corrupción. Si el Estado no tiene autoridad para restringir las exportaciones u otorgar licencias a los hombres de negocios, nadie pagará sobornos en estas áreas. Si un programa de subsidio se elimina, los sobornos 
que le acompañaban desaparecerán también. Si se elimina el control de los precios, los precios de mercado pondrán de manifiesto la escasez de valores, no la existencia de sobornos. Si un paraEstado es el lugar de los pagos corruptos, trasladarlo al sector privado eliminará la corrupción.

Por ejemplo, aunque las empresas implicadas en el comercio extranjero estén a menudo implicadas en la corrupción, la reforma en las reglas de procesos de exportación parece haber reducido la corrupción de los exportadores por debajo de la de los no exportadores (Rose-Ackerm An y STONE, 1996). Tras un corto experimento con prohibición, EE.UU. anuló la 18. ${ }^{a}$ enmienda a la Constitución, prohibiendo la manufactura y venta de sicores intoxicantes». Durante el tiempo en que estuvo en vigor, entre 1919 y 1933, fue un periodo de producción y venta ilegal de alcohol de forma extendida, y se produjo la corrupción de los empleados encargados de ejecutar dichas leyes. El debate sobre la legalización de las drogas en el mundo industrial hace referencia a la posibilidad de controlar la industria a través del Derecho penal. Las apuestas, una vez prohibidas en muchas jurisdicciones, han sido recientemente legalizadas en muchos países y Estados en EE.UU., aunque sujeta a una fuerte supervisión estatal e incluso propiedad del Estado.

En general, cualquier reforma que incrementa la competitividad de la economía ayudará a reducir los incentivos corruptos. Así, las políticas que aflojan los controles del comercio exterior eliminan las barreras de entrada para la industria privada, y privatizan las empresas estatales, de tal forma que se asegure una competitividad que contribuirá a combatir la corrupción. Tales reformas tambien animarán a las empresas a moverse de la sombra informal de la economía al sector formal, donde pueden obtener acceso al capital a los índices de los mercados y pueden regular e imponer impuestos de forma efectiva. En general, ir bajo tierra es un sustituto de los sobornos, aunque a veces las empresas sobornan a los empleados públicos para evitar el status de los empleados. El nexo entre la regulación estatal intrusiva, la corrupción, y la economía informal en U crania está documentada en Kaufmann (Kaufmann, 1994; y Kaliberda, 1996).

Pero cualquier movimiento hacia la desregulación y la privatización debe llevarse a cabo con cuidado. D esregular en un área puede incrementar la corrupción en otra. Por ejemplo, un esfuerzo con éxito para reducir la corrupción en el transporte de productos agrícolas en un país africano aumentó la corrupción en países vecinos en la misma ruta de transporte ${ }^{15}$. El proceso de privatización en sí mismo, al igual que las nuevas instituciones reguladoras que serán necesarias en el mundo privatizado pue den ser corruptas. En vez de sobornar al Estado para obtener contratos y un trato favorable, los que pujan para la compañía sobornan a los empleados en el órgano de privatización. Los de dentro obtienen un trato especial (M ANZETTI y BALKE, 1996; Celarier, 1996). La integridad del proceso de privatización es especialmente un problema en los países en transición. El riesgo es no sólo la corrupción y los negocios de los que están dentro, sino el dominio por parte de los grupos de crimen organizado, que echan a los competidores, sobre todo de las empresas occidentales. Así, parte del proceso de privatización debe ser el establecimiento de un ambiente legal transparente y de confianza. Esto no se hizo en muchos de los países que ya se han privatizado con resultados previsibles (ROSE-ACKERM AN, 1994; SHELLEY, 1994). La privatización y la desregulación son deseables en una amplia gama de casos, pero los reformadores necesitan mirar con detenimiento los incentivos para la búsqueda de rentas existentes (ROSE-ACKerman, 1996).

Muchos programas reguladores y de gasto tienen importantes justificaciones y deben ser reformados, no eliminados. La corrupción en la recaudación de impuestos obviamente no pueden solventarse fracasando a la hora de recaudar los ingresos. En tales casos, una solución es clarificar y fijar las leyes necesarias de forma que reduzcan la discrecionalidad de los empleados. El servicio de aduanas mejicano, por ejemplo, redujo el número de pasos en el proceso de aduana en el aeropuerto de la ciudad de M éico de dieciséis a tres (El Economista, 13 de febrero de 1992; Reuters N ews Service, 24 de febrero de 1993). Los reformadores han sugerido a menudo que los empleados favorezcan los productos que están fuera de la balda vendidos en mercados privados y que los sistemas de impuestos y de subisidio se simplifiquen (ROSE-ACKERM AN, 1978).

Las reglas podían hacerse más trasparentes con justificaciones proporcionadas públicamente. El gobierno podría favorecer unas leyes de gasto, fiscales y reguladoras no discrecionales simplificadas como forma de limitar las oportunidades de corrupción. El Estado podría utilizar los precios de los mercados privados como indicadores para juzgar los contratos públicos (RuzIN DANA, 1995). Podrían establecerse normas claras de comportamiento adecuado, de tal forma que las violaciones pudieran percibirse incluso si no se percibieran los sobornos. En aquellos casos en que se adopten decisiones cuidadosamente, éstas pueden favore cer artículos estándar para proporcionar un indicador y el coste menor de pujar.

El valor de dicho tipo de reformas depende de los costes de limitar la flexibilidad de los empleados públicos. Pero en los páses pobres que carecen de personal entrenado, la simplificación de las políticas públicas tiene especial interés. Sin embargo, a veces, el riesgo de corrupción deberá ser tolerado por los beneficios de una aproximación caso por caso para programar la administración. La transparencia y la publicidad pueden ayudar a supe rar los incentivos corruptos incluso en tales casos, pero sólo si existen los sistemas de responsabilidad discutidos a continuación. Si no existen, reglas simples y claras pueden permitir a un líder en los niveles superiores extraer pagos de forma más efectiva.

Los economistas han recomendado desde hace tiempo reformar las leyes reguladoras en áreas tales como la protección medio- 
ambiental introduciendo fórmulas basadas en el mercado que limitan la discrecionalidad de los reguladores. Los analistas también han recomendado tarifas de usuario para servicios escasos del gobierno. Estas reformas tienen la ventaja de eliminar los incentivos de corrupción sustituyendo los sobornos por pagos le gales. La venta de agua y los derechos de alimentación, los dere chos en materia de polución sobre los que quepa el comercio, y la venta de licencias de importación y exportación pueden mejorar la eficiencia de los operadores del gobierno a la vez que limitan la corrupción. Sin embargo, los países pobres cuyas normas reguladoras existentes apenas se ejecutan pueden tener dificultades a la hora de establecer tales reformas, dado que en la actualidad los violadores de tales normas no están corriendo con los gastos de las normas existentes.

Por último, la reforma administrativa puede reducir los incentivos corruptos. La corrupción a menudo se enmarca en la estructura jerárquica de la burocracia. Los empleados de bajo nivel recaudan los sobornos y pasan una porción de los mismos a los empleados de alto nivel, quizá bajo la forma de un pago por encima de la mesa por el trabajo en sí mismo (W ADE, 1982). En contraste con esto, los empleados de alto nivel pueden organizar y racionalizar el sistema corrupto para evitar el desgaste de competencia entre los empleados públicos de bajo nivel. Los empleados de alto nivel pueden entonces compartir las ganancias de su habilidad organizacional con los subordinados, quizás utilizándolos para realizar encargos, tranferencias de fondos y para que realicen otros trabajos arriesgados que les exponen a poder ser arrestados. Romper tales patrones puede requerir un esfuerzo re organizacional fundamental.

Una posibilidad es la introducción de presiones competitivas dentro del gobierno para reducir el poder de regateo delosempleados indivuales. Cuando se pagan sobornos por tales beneficios como licencias y permisos, queno estan constreñidos delos correspondientes límites presupuestarios, la confluencia de jurisdicciones burocráticas competitivas puede reducir la corrupción. D ado que los clientes pueden acudir a cualquiera de los empleados eir a un segundo empleado si le rechaza el primero, ningun empleado tiene mucho poder de monopolio. D eesta forma, ninguno puede extraer un pago muy grande. Para los clientes cualificados los sobornos no serán mayores queel coste de reaplicación. Losclientes no cualificados seguirán pagando sobornos, pero ni siquiera ellos pagarán tanto siempreque, también, puedan acudir a otro empleado público. Si algunos empleados establecen reputaciones honestas, los solicitantes cualificados preferirán a dichos empleados, reduciendo así las ganancias a los corruptos. Esta reducción en los ben eficios respecto de los restantes empleados corruptos puedeinducir a ciertos empleados marginales a pasar a ser honestos, reduciendo así más aún los beneficiosqueles corresponden a los restantes funcionarios corruptos, y aśí. Un número de empleados honestos puedeechar abajo el sistema corrupto si la congestión no es un problema serio (ROSE-AcKerm An, 1978). Si, en cambio, aquellos que pagan sobornos no son cualificados, la honestidad de algunosempleadosaumentarálas ganancias deaquellosqueson corruptos, induciendo a más a volverse corruptos.

Cuando los empleados, tales como los oficiales de polícía, pueden imponer costes, se debería tomar en consideración otro modelo de confluencia de jurisdicción. A los agentes de policía que buscan controlar los negocios ilegales se les pueden aplicar distintas áreas confluyentes de ejecución. De esa forma los que apuestan y los traficantes de drogas no pagarán mucho a un solo policía dado que un segundo policía puede venir después y exigir un pago. El primero de ellos simplemente no puede proporcionar la protección (ROSE-ACKERM AN, 1978). Este sistema puede funcionar mejor si los agentes encargados de la ejecución de las leyes pertenecen a distintas fuerzas de policía - local, estatal, 0 federal, por ejemplo- . La colusión entre agentes para vencer al sistema será menos probable. El FBI esta implicado en la investigación de la corrupción a nivel municipal en EE.UU. La Comisión de Auditoría Británica es una agencia gubernamental nacional con autoridad paravigilar la honestidad delos gobiernos locales (Comisión de Auditoría de Gran Bretaña, 1993). A veces, la confluencia tiene una dimensión internacional. La implicación de las autoridades encargadas de la ejecución de las normas en materia de drogas en EE.UU. en la investigación del negocio de droga en Colombia llevó a un desertor a elegir el sistema judical norteamericano por encima del colombiano para abrir la puerta a la información sobre los carteles de pago de droga a políticos colombianos (TheWashington Post, 28 de enero de 1996).

\section{Estableciendo una ejecución de las leyes créble}

Una condición básica para el control de la corrupción es la existencia de un marco legal viable que ejecute las leyes sin favoritismo político 0 arbitrariedad. El objetivo es tanto detener a aquellos que se sienten tentados a involucrarse en actos corruptos como educar al público para que se enfrente a la conducta criminal de los empleados. Leyes duras no son suficientes. Muchos países altamente corruptos tiene estatutos formales ejemplares que no tienen ningún significado real porque rara vez se ejecutan. Un pás que se tome en serio la reforma debe tener cuerpos de investigación y condena efectivos y un efectivo siste ma judicial que no sea en sí mismo corrupto.

Un poder judicial independiente puedeser deincalculablevalor a la hora de comprobar las conductas ilegales de los empleados. En India el Tribunal Supremo impulsó una investigación de corrupción que el gobierno había tratado de suspender (Times, 2 de marzo de 1996). En Brasil la insistencia del Tribunal Supremo en que el voto congresista del proceso de destitución por corrupción fuera público ayudó a mantener el proceso como un proce so honesto (GEDDES y RIBEIRO N ETO, 1992). La reformadel poder judicial requiere mucho más que un simple cambio del personal. 
Sin un cambio de las condiciones subyacentes es poco probable que se dé un importante cambio fundamental. El primer paso en esa reforma es el salario y las condiciones laborales de los jueces y del personal de apoyo, pero esto debe acompañarse con una me jor vigilancia de su actuación, tanto dentro del sistema como por parte de gente externa al mismo. La información de retrasos en función del tipo de caso y del tribunal podría recogerse y hacerse pública.

Una preparación adicional puede ser necesaria para los jueces si se deben enfrentar deforma responsable con las disputas que se presentan ante su tribunales. Un aumento en la profesionalidad de los jueces debe reducir la incidencia de la corrupción. Pero todas estas reformas tendrán poco impacto si no se garantiza la independencia del poder judicial respecto del poder ejecutivo y legislativo. La independencia se consigue de varias formas por todo el mundo. Cualquiera que sea el mecanismo utilizado, el objetivo es un poder judicial quetenga limitados sus poderes constitucionalmente, pero aislado de las presiones políticas del día a día. El poder judicial puede jugar un papel no sólo oyendo los casos de corrupción que se presentan ante él por parte de las autoridades estatales, sino tambien ayudando a los ciudadanos a revisar las acciones del Estado. En aquellos países en los que el poder judicial proporciona una voz independiente al Estado de D erecho, los intentos por parte de los ciudadanos de requerir al ejecutivo que obedezca a la ley pueden ser útiles como herramienta suplementaria. El Banco M undial está empezando a trabajar en la reforma judicial, sobre todo en Latinoamérica, pero los proyectos están todos en su fase inicial (RowAT, M ALIK y D AKOLIAS, 1995), y puede que no se centren lo suficiente en la contribución global a la reforma del gobierno.

Una forma de hacer queel poder judicial trabajedeforma más efectiva estener leyes queestén bien redactadasy quesean suficientemente claras. Por supuesto, los tribunales no pueden evitar ejercitar poder discrecional, pero la claridad eliminará las disputas y hará que las decisiones judiciales parezcan menos arbitrarias. En algunos países en desarrollo las leyes se escriben en el idioma del anterior poder colonial y son difíciles de entender para los ciudadanos. Incluso en aquellos casos en los queel idioma de los estatutosno es un problema, algunos países siguen manteniendo estatutosobsoletostomados prestados de paísesindustriales hacemuchos años. Así, aunque se pueden reducir algunos incentivos corruptos reformando y poniendo al día al sistema judicial en sí mismo, una reforma comprensiva tambien requieredeuna revisión del sistema legal en el que operan los jueces.

Pero la reforma judicial tendrá poco impacto salvo que el sistema de condenas opere de forma efectiva. Cuando las agencias ordinarias de ejecución de la ley son inefectivas o corruptas, una alternativa es la creación de una comisión independiente anticorrupción o el nombramiento de un inspector general que sólo dé cuentas al jefe del jefe 0 al Parlamento. La comisión más conocida es la Comisión Independiente contra la Corrupción de H ong
Kong (ICAC), que da cuentas sólo ante el Gobernador General y que tiene poderes extensivos (KLITGAARD, 1988; Q UAH, 1993; M ANION, 1996). A la Comisión se le encarga investigar las alegaciones de corrupción y tambien tiene una misión educacional. Los informes llevados a cabo entre 1977 y 1994 indican que las percepciones públicas de la corrupción descendieron en los primeros años de la ICAC, y las pruebas indirectas sugieren que también lo hizo la corrupción, de hecho, bajó junto a las apreciaciones públicas. 0 tros países, tales como Singapur, M alasia, Botswana, Malawi y el Estado australiano de Nueva Gales del Sur (SKIDM ORE, 1996), tienen instituciones similares. Sin embargo, el ICAC no carece de aspectos problemáticos. Sus extensos poderes podrían ser objeto de abuso en sistemas menos comprometidos con el Estado de Derecho. El caso de Hong Kong indica que una agencia anticorrupción independientey dura pue de ser una potente herramienta siempre que represente un compromiso créble a largo plazo e incluya límites en su capacidad para utilizar los fines políticos de forma abusiva.

Reformar la ejecución de las leyes y el poder judicial puede estar más allá del alcance de los países pobres en los que la corrupción es endémica. En esos casos la reforma requerirá centrarse en reformas sustantivas dibujadas con carácter general en la sección previa y también en estrategias que aumenten la responsabilidad del Estado frente a los ciudadanos ordinarios.

\section{Reformando el funcionariado}

M uchos países en vías de desarrollo tienen funcionarios muy mal pagados. Los empleados complementan su sueldo con segundos trabajos o con pagos. Un estudio reciente reveló que existía una correlación negativa entre los salarios del funcionariado (relacionados con los salarios del sector privado) y el nivel de corrupción (VAN RIJCKEGHEM y WEDER, 1996). LOS proyectos de reforma del funcionariado apoyados por el Banco M undial deberían incluir una preocupación explícita por reducir la corrupción (N umberg y N eLLIS, 1995). La reforma del funcionariado requerirá generalmente de un esfuerzo a fondo, sobre todo si el sistema ha caído en una trampa, en cuyo caso los altos niveles de corrupción generan incluso niveles de corrupción más altos.

Si a los empleados se les paga mucho menos de lo que se paga a gente con un entrenamiento similar en otros lugares de laeconomía, sólo aquellos que estén dispuestos a aceptar sobornos se sentirán atrádos al sector público ${ }^{16}$. El salario del funcionariado deberíafijarseal menosal mismo nivel queel de puestos similares en el sector privado, paraasí hacer posibleel reclutamiento basado en losméritosy permitir a aquellos seleccionados servir sin recurrir a la corrupción. Si los beneficios bajo control de los empleados son valiosos, sin embargo, la paridad puedeno ser suficiente. En cambio, los salarios de los funcionarios pueden necesitar situarse por 
encima del salario del sector privado, con generosos beneficios, tales como pensiones, que serán recibidos sólo si el trabajador se jubila con una buena reputación (BECKER y STIGLER, 1974). Sin embargo, rara vez será posible subir el salario del funcionariado a niveles que reflejen los beneficios discrecionales bajo el control de los empleados. La experiencia del mundo industrial sugiere que una solución tan cara es innecesaria. Puede ser suficientepagar ala gente lo bastante para equipararse a los trabajos del sector privado que requieran habilidades similares (VAN RIJCKEGHEM y W EDER, 1996). Sin embargo, esta estrategia debe combinarse con una efectivo sistema devigilancia y un sistema basado en el mérito y transparencia en la selección de los funcionarios. Las sanciones deben anudarseúnicamentea los beneficios marginales de aceptar pagos. Paralelamente, en aquellos casos en los que el único coste de eficiencia de la corrupción surge de su ilegalidad, se deberían legalizar lospagos. En el diseño detalessistemas, sin embargo, es importante evitar dar a los burócratas un poder de monopolio que puedan utilizar para conseguir niveles muy altos de rentas.

Una de las razones de que haya decrecido el salario del funcionariado tan rápidamente en los últimos años es la presión fiscal que hay sobre los gobiernos. Una reducción de salario de carácter general, que a menudo se ha conseguido a través de la inflación, es políticamente más fácil de manejar que el despido selectivo de trabajadores. Y los países que están haciendo un buen progreso en alcanzar un equilibrio fiscal pueden poner en peligro su éxito cediendo a la presión de los funcionarios para aumentar los salarios con carácter general. Por ejemplo, en 1992, antes de una elección, Ghana aumentó los salarios de sus funcionarios en un 80 por ciento (Banco M undial, 1995). Los obstáculos políticos de una efectiva reforma del funcionariado a menudo son graves.

\section{Aumentar la responsabilidad frente a los ciudadanos}

El sector privado puede ser un límite importante al ejercicio arbitrario de poder por parte del gobierno, pero sólo si los individuos pueden descubrir lo que está haciendo el Estado y utilizar dicha información para responsabilizar a los actores públicos.

Como primer paso, losgobiernos deben publicar presupuestos, recaudaciones de ingresos, estatutos y normas y las actuaciones de los cuerpos legislativos. Los datos financieros deberían ser auditados de forma independiente. Los fondos secretos disponibles para los jefes ejectutivos y los ministros a la cabeza son una invitación a la corrupción. Varios proyectos del Banco M undial y del UNDP han ayudado a economías en transición y a países en desarrollo a publicar documentos exactos cada cierto tiempo sobre las operaciones básicas del Estado. O tros han ayudado a países, especialmente en Latinoamérica y África, a reformar sus procesos de contabilidad y presupuestariospara hacerlosmás transparentes (Banco M undial, 1995). Estas reformas proporcionan un escenario importante para los esfuerzos anticorrupción.
Las cuidadosas regulaciones deben mantener el proceso abierto y justo (PoPE, 1996). M uchos escándalos en ese sentido ocurrieron bien porque los altos empleados rechazaron el consejo 0 los empleados subordinados acusaron de operar con licitaciones y contrataciones del Estado y sin los controles formales. Estas reglas, sin embargo, no deben percibirse como tontas o excesivamente intrusivas. Por ejemplo, las reglas que señalan queal licitador a la baja siempre se le debe aceptar pueden conducir a un trabajo de baja calidad o pueden facilitar licitaciones fraudulentas (ver K LITGAARD, 1988). Transparency International, una organización internacional sin ánimo de lucro, que se comprome tió a luchar contra la corrupción por todo el mundo, ha recomendado a los potenciales pujantes que firmen un «pacto de integridad», bajo el cual prometerán apartarse de la corrupción. Tales promesas parecen reiterativas, dado que la corrupción es ilegal, pero tienen la ventaja de resaltar el problema en países con poco respeto por las leyes formales. Sin embargo, un intento serio de implementar un pacto de integridad requerirá de un mecanismo de quejas institucionalizado.

Los contratistas desilusionados son una importante fuente de información de cualquier sistema de integridad. En general, la existencia de perdedores con un gran interés en el resultado, tales como los licitadores desilusionados, puede facilitar los esfuerzos para limitar la corrupción (ALAM, 1995). Sin embargo, los perdedores tienen un incentivo, el de acusar a los ganadores de corrupción incluso si no ha ocurrido. Los países necesitan hacer un uso constructivo de la información que los contratistas les proporcionan sin mezclarse en la investigación de las reclamaciones de cada licitador desilusionado. La comunidad internacional puede tener que ayudar considerando la posibilidad de la creación de un foro para escuchar tales quejas.

Aquellos que pierden a raíz de la corrupción pueden verse envueltos en esfuerzos anticorrupción de otras formas. En ocasiones los pagadores de sobornos son los propios perdedores que estarían mejor en un mundo honesto. Se sienten las víctimas de la extorsión. Tales pagadores de sobornos pueden ser aliados potenciales en un effuerzo anticorrupción, pero necesitan mecanismos a través de los que manifestar sus quejas. En este sentido, el Banco Mundial puede ayudar a los países a experimentar con tribunales de bajo nivel y a los defensores del pueblo que buscan contrarrestar la falta de poder de la gente ordinaria que se ve enfrentada con la rutina de la exigencia de sobornos. Una alternativa es la creación de «íneas calientes», a través de las cuales los ciudadanos pueden quejarse directamente al gobierno. M éico ha establecido un sistema así para los negocios puestos en peligro por los inspectores (Poder Ejecutivo Federal de M éico, 1996), y el Estado de Chihuahua ha experimentado con un programa similar para combatir la corrupción policial.

La información es una condición previa para los esfuerzos anticorrupción. Los actos de libertad de información en EE.UU . y en un número de países europeos contribuyen a una efectiva vi- 
gilancia pública general. Estas leyes permiten a los ciudadanos solicitar información sin tener que demostrar que la información afecta a su situación personal. Pero descubrir lo que está pasando es de poco valor, salvo que la gente utilice esos conocimientos para ejercer influencia sobre el gobierno. En los países sin sistemas electorales democráticos o sin tribunales independientes, se necesita favorecer otras formas de que se escuche a los ciudadanos. Por ejemplo, las agencias ejecutivas podrían celebrar audiencias tanto a nivel nacional como a nivel local, de tal forma que aquellos que se beneficien o que sufran una politica gubernamental puedan ser oídos. En este caso los procedimientos de ope ración estándar del Banco Mundial pueden ser demasiado centralizados para ben eficiarse de una consulta a niveles inferiores. La publicidad a través de los medios de comunicación es una opción importante. Es probable que incluso un líder no democrático sea sensible a la opinión pública. El Instituto de D esarroIlo Económico del Banco M undial ha empezado en este ámbito con programas educacionales para periodistas africanos para enseñarles cómo implicarse en reportajes de investigación.

Para ver como un proceso de responsabilidad puede funcionar en un país en vías de desarrollo, consideren la descripción que hace O LDENBURG (1987) de un esfuerzo con éxito para controlar la corrupción en el proceso de consolidación de la tierra en Uttar Pradesh en India en los años ochenta. Las claves fueron un proceso abierto con la participación real de aquellos afectados, una presión de tiempo, y apelaciones rápidas y justas. Los empleados del gobierno dirigieron el proceso, pero nadie pudo proseguir con la plantación hasta que estuvo completado el sistema de distribución de la nueva tierra. Los propietarios de fincas insatisfechos podían apelar y obtener decisiones rápidas que los participantes veían con carácter general como justas.

Los individuos se enfrentan a un problema de freerider (gorrón) a la hora de buscar controlar los procesos políticos y burocráticos y limitar las actuaciones ilegales. La información puede estar disponible en principio, pero puede que nadie tenga un incentivo para examinarla. Las leyes que facilitan el establecimiento de asociaciones de vigilancia y sin ánimo de lucro ayudarán. Algunos países se preocuparon de que se pudieran utilizar algunas organizaciones no gubernamentales para controlar su actuación, que pudieran limitar tales grupos o hacer muy costosa su organización. Las limitaciones legales pueden ser muy altas, y los grupos y sus miembros pueden estar sujetos a vigilancia y a ataques. El Banco debería ayudar a los países a promulgar estatutos permisivos que rijan la incorporación de organizaciones sin ánimo de lucro.

Cuando tales organizaciones existen, éstas pueden tener un papel muy constructivo. Por ejemplo, con la ayuda del Banco M undial y de las agencias de ayuda bilaterales, las secciones locales de Transparency International han organizado reuniones de trabajo integrados en varios países. Estos grupos de trabajo reúnen a gente preocupada con estos asuntos del sector público y del sector privado para discutir el problema de la corrupción. Las organizaciones sin ánimo de lucro también pueden llevar a cabo y publicar informes que revelen las actitudes públicas hacia los servicios del gobierno. Un trabajo pionero se ha llevado a cabo por el Centro de Asuntos Públicos de Bangalore, India, que produce «tarjetas de información» sobre los servicios que se realizan a los pobres urbanos en cinco ciudades. Reveló que el dinero «rápido» era omnipresente, con hasta un tercio de los que daban información señalando que necesitaban sobornar para obtener servicios (PAul, 1995).

\section{Conclusiones}

¿D ónde deberían comenzar esos esfuerzos de reforma? Los países que se toman en serio la lucha contra la corrupción reque rirán de un detallado análisis específico por cada país que siga las líneas de los recientemente completados por el Banco M undial para Bangladesh y Nigeria, pero es posible realizar una serie de comentarios generales. El primer paso es descubrir dónde está imponiendo la corrupción los mayores costes. Aquí hay varias posibilidades comunes:

- Losingresosdelosimpuestosy aduanas deben estar muy por debajo del nivel que se necesita para llevar a cabo los servicios básicos del gobierno, y el modelo de pagos puede ser muy injusto al haber despidos. Las opciones incluyen simplificar las leyes fiscales para reducir el poder discrecional burocrático y reorganizar la burocracia para mejorar la vigilancia general y los incentivos por el buen comportamiento.

- La regulación de los negocios puede ser tan compleja, y que gaste tanto tiempo, e intrusiva que el desarrollo de un sector privado saludable se vea afectado. Aquí la respuesta está en ver con detalle las leyes para ver cuáles pueden ser eliminadas o simplificadas y cuáles requie ren de una mejor ejecución. Muchos países tienen regulaciones de negocios sin sentido, combinadas con una ejecución inefectiva en áreas sociales beneficiosas, tales como la protección medioambiental.

- O tro patrón costoso es la promoción estatal de los proyectos de infraestructura que son demasiado amplios y complejos. El coste de la corrupción no son los sobornos en sí mismos, sino el coste de la ineficiencia de los proyectos. Incluso si hay pruebas directas disponibles de corrupción, la escala inapropiada y el diseño de estos proyectos debería justificar su cancelación. Tales cancelaciones deben, sin embargo, ser combinadas con procedimientos mejorados por futuras aprobaciones de proyectos. 
Las reformas institucionales básicas pueden ser necesarias como precondición para una reforma en determinados sectores. He resaltado la importancia de las reformas que mejoren la responsabilidad del gobierno frente a los ciudadanos ordinarios. Incluso si uno mantiene constante la estructura constitucional de una nación, hay una gama de reformas que pueden ser políticamente difíciles pero que no son especialmente caras. El problema es institucionalizar tales reformas, de tal forma que soporten los cambios en el personal y en la coalición política. La reforma debe incrementar la transparencia y la responsabilidad de las operaciones del gobierno y facilitar la organización de grupos de vigilancia independientes, y las mismas agrupaciones comunitarias.

Incluso, si seha hecho frentea losproblemas de política sustantiva y de estructura institucional, la mayor parte de los países en desarrollo deben enfrentarseala difícil tarea de reformar el funcionariado. Esto será o financieramente costoso o políticamente doloroso, pero es una parte necesaria de cual quier esfuerzo serio de reforma. Las políticas de reforma deben reducir el tamaño del funcionariado, deben pagar salarios de base decentes a aquellos que se queden, deben establecer un sistema de reclutamiento basado en los méritos, y un desarrollo efectivo del «palo y la zanahoria» (carrots and sticks) que proporcionen a los empleados un incentivo para ser honestos y para trabajar eficientemente. Esto es, por supuesto, mucho más fácil decirlo que hacerlo, sobre todo en los paísespobres, donde se espera que losfuncionarios sostengan a sus ampliasfamilias. La experiencia del Banco M undial en esteámbito, incluso en casos en los que los proyectos no han tenido éxito en último término, debe estar ampliamente disponible.

La falta de instituciones creíbles capaces de escuchar las quejas y ejecutar las leyes es el punto débil de las instituciones en muchos países en vías de desarrollo y en economías en transición. Así, un área para la reforma debería ser la mejora de las instituciones existentes, tales como los tribunales, o la creación de nuevos cuerpos, tales como inspectores general es independientes o comisiones anticorrupción. La experiencia de otros países - tanto las de éxito como aquellas que fracasaron cuando los luchadores nominales de la corrupción se volvieron ellos mismos corruptos- necesitan ser entendidas. A la hora de proponer nuevas instituciones nos debemos enfrentar al problema de las campañas anticorrupción que se están utilizando para debilitar a los oponentes políticos y para disciplinar a aquellos problemáticos.

El cambio fundamental requiere de un compromiso a largo plazo desde arriba. Incluso si el marco constitucional básico no está abierto al cambio, la reforma seria puede llevarse a cabo dentro de la estructura del gobierno existente. Los gobiernos que hacen difícil que se alcen en crítica las voces independientes, sin embargo, tendrán una especial dificultad a la hora de establecer un compromiso créble con un gobierno honesto y transparente. Esos gobiernos pueden moverse rápidamente en un corto plazo de tiempo, pero siempre corren el riesgo de que se revierta la política en el futuro.
¿Cómo debería el Banco M undial, teniendo en cuenta sus límites presupuestarios, ayudar en el proceso de reducción de la corrupción en los países en vías de desarrollo? Las prioridades son difíciles de establecer en abstracto, pero es posible realizar una serie de observaciones.

- El Banco necesita dejar mucho más claro que en el pasado que no se aceptará la corrupción como algo normal en sus propias ganancias y préstamos, y debe avanzar y cancelar los proyectos en los que la corrupción se haya descubierto 0 en que los costes sugieran que la venalidad prevalece. D ebe ser escéptico a la hora de apoyar proyectos que facilitan que los empleados públicos oculten ganancias privadas, y puede que necesite dejar de prestar ayuda en aquellos países en los que la corrupción en los altos niveles parece endémica.

Recientes informes internacionales se centran en reducir los sobornosen la negociación internacional y comprobar el flujo de fondos ilícitos. Las estrategias incluyen tratados internacionales y acciones por parte de organizaciones multinacionales, tales como la 0 rganización para la Cooperación Económica y el Desarrollo y laO rganización deEstados Americanos, «esfuerzospor convencer a los países de la necesidad de sancionar los sobornos fuera de sus fronteras», y el desarrollo de códigos empresariales de conducta. El Banco debería apoyar tal es esfuerzos internacional es para limitar la corrupción e impulsar los esfuerzos internacionales para establecer estándares presupuestarios, de «contabilidad» y de licitación y contratación.

Los proyectos de becas y préstamos deberían centrarse cada vez más en crear un ambiente favorable para el crecimiento compartido y el alivio de la pobreza. El Banco M undial tiene la experiencia en reforma gubernamental, pero su trabajo necesita ser evaluado por las lecciones que puede proporcionar. Los proyectos deberían diseñarse de tal forma que los empleados de cada país trabajaran junto con el personal del Banco Mundial para aislar los problemas más graves y diseñar soluciones en línea con las posibilidades establecidas en general más arriba. El Banco debió seleccionar a unos cuantos países con gobiernos que apoyan y trabajar con ellos para diseñar programas que sirvan de ejemplo para el futuro. El Banco no debería apoyar aquellas reformas menores que benefician a los autócratas corruptos.

Al Banco M undial le preocupan los proyectos que no son suficientemente «propiedad» de países que los toman prestados. La concentración en la materia de corrupción da un toque irónico a esa preocupación. «La propiedad» en los puestos altos no es deseable si el patronazgo y la corrupción son comunes o si los proyectos ayudan a mantener tales regímenes en el poder. En tales 
casos no es muy probable que los proyectos con el mayor potencial de «propiedad» se dirijan a los más pobres 0 en general a los objetivos de desarrollo. Dado que el Banco M undial es una institución de desarrollo, debería tratar de contrarrestar las distorsiones introducidas por los deseos de los líderes y de sus patrones para amasar riquezas para ellos mismos. Ayudar a los países a desarrollar estrategias anticorrupción puede tanto mejorar la le gitimidad y la efectividad de los gobiernos como ayudar en el desarrollo, haciendo más fácil fijar proyectos que hagan frente a la pobreza y faciliten el crecimiento compartido.
Artículo traducido por Cristina Alba M uñoz.

* Professor of Law and Political Science. Yale University. Las ideas presentadas en este trabajo han sido ampliamente desarrolladas en mi libro Corruption and Government: Causes, Consequencesand Reform, Cambridge University Press, 1999.Trabajo preparado para la Conferencia Anual sobre el Desarrollo de la Economía del Banco M undial, Washington, D.C., 30 de abril y 1 de mayo, 1997. Los hallazgos, interpretaciones y conclusiones expresados en este trabajo son enteramente los de su autora. No representan necesariamente los puntos de vista del Banco M undial, o los de sus D irectores Ejecutivos, ni los de los países que representan.

1 M AURo $(1995,1997)$ demuestra que los altos niveles de corrupción se asocian a bajos niveles de inversión como parte del GDP en varios países. Un mejor estándar (2.4) en el índice de corrupción se asocia con un aumento de más de un 4 por ciento en el índice de inversión y un aumento de más de medio porcentaje de punto en el índice de crecimiento anual per cápita GDP (M AURo, 1997).

2 Un índice del nivel de riesgo en la inversión de un país, basado en once factores del Índice de Negocios Internacional (incluido el índice de corrupción), se asoció con los índices de inferior inversión y los índices de menor crecimiento (M AURO, 1995). KeEfer y Knack (1995) descubren que un índice sobre la cualidad de las instituciones gubernamentales es un factor determinante de la inversión y el crecimiento de gran importancia.

${ }^{3}$ Los datos proceden de Grupo para la Reforma de los Precios, que forma parte del Instituto de Finanzas y Comercio, de la Academia de Ciencias Sociales de China. Publicado en Zhongguo Wujia (China Price) 0 ctober 1990, Beijing.

4 Las entrevistas con hombres de negocios en Europa O riental y Rusia indican que a menudo se necesita realizar dichos pagos para obtener el crédito. (D EM M ELO, O fer, y Sandler, 1995; Webster, 1993; Webster y Charap, 1993). En Líbano un estudio similar reveló que los préstamos no estaban a disposición de la gente sin el pago previo de sobornos (Yabrak y W ebster, 1995).

5 Un estudiante de programas de microfinanzas, M arguerite ROBIN $50 \mathrm{~N}$, descubrió que aquellos programas que proporcionan un crédito por debajo del valor de mercado a los pobres de las zonas rurales, a menudo eran corruptos y sólo proporcionaban ayuda a las élites ( «N ew Bank Lends Support to Vietnam's Rural Poor», Reuters World Service, 18 de agosto 1995.)

${ }^{6}$ Estudios promocionados por el Banco M undial respecto de hombres de negocios dePakistán y U crania indican que existe una gran variabilidad entre empresas (RoSEACKerman y StOne, 1997).

7 El ministro fija un objetivo de ingresos, una tabla de responsabilidad nominal por el impuesto, y el índice de ingresos del recaudador de impuestos. La corrupción otorga a los recaudadores de impuestos un incentivo para buscar el ingreso del im- puesto y se tolera siempre que el recaudador entregue una cantidad igual al objetivo de ingresos (Flat Ters y M ACLEOD, 1995).

8 La inseguridad juridical y reguladora se menciona a menudo por los hombres de negocios entrevistados en los estudios en el mundo desarrollado (Economisti Associati, 1994; Stone; 1995; Webster, 1993; Webster y Charap, 1993); Pritchett y Sethu (1994) muestran cómo los índices de tarifas superiores se asocian con recaudaciones proporcionalmente menores y una mayor variación en los índices que se pagan.

9 Si se asume que las burocracias estatales están hechas de forma ineficiente, y que el grado de regulación o de impuestos que imponen es excesivo, surgen tres posibles beneficios de la corrupción» (O xford Analytica, 1996) Los sobornos pueden permitir que los proyectos más beneficiosos vayan a la cabeza, pueden limitar una regulación excesiva, y reducir el pago del impuesto.

10 Dicha ley es la Ley de Prácticas Corruptas Extranjeras, 15 U.S.C. $78 \mathrm{~m}$ (b) \& (g)(h), 78dd-1, 78dd-2, $78 f f$ (a) \& (c) (1988 \& Supp. IV 1992). Ver Pen dergast (1995). 11 Ver Coolid ge y Rose Ackerman (1996). Sobre la orientación de la corrupción de las concedentes de madera en M alasia, ver V IN CENT y BIN KLEY (1992). D EACON (1996) señala que la inseguridad en la propiedad y los débiles derechos de propiedad están negativamente asociados a los índices de desforestación.

12 Por ejemplo, las compañías implicadas en la privatización de la electricidad y las telecomunicaciones en M alasia se quejaron de que el gobierno seguidamente admitió a competidores adicionales con fuertes lazos políticos. Financial Times, 13 de octubre de 1995.

13 De acuerdo con un inglés que vivía en Egipto en los años 1820, las decisiones judiciales se veían influenciadas por el rango de los partidos o por el soborno de cualquiera de ellos. «En algunas ocasiones, especialmente en los procesos judiciales largos, se dan sobornos por cada una de las partes procesales, y se emite una decisión a favor de aquel que haya pagado el soborno superior» (JOHNSON, 1991: 686).

14 D e acuerdo con el gobierno ruso, 269 hombres de negocios y financiadores fueron asesinados en 1995 en asesinatos similares a ejecuciones (The Economist, 9 de noviembre de 1996).

15 Un proyecto promocionado por un USAID redujo el número de puntos de vigilancia sobre las extraciones de sobornos a lo largo de las rutas de la cebolla en N iger. D esafortunadamente, el resultado final fue un aumento de los pagos y de los niveles de impuestos en Coté d'Ivoire ya que las cebollas acercaron los mercados de alimentos de Abidjan (ROGERS e IDDAL, 1996).

16 El status de Botswana es el de un país africano relativamente limpio. Puede provenir del compromiso de sus líderes por un funcionariado profesional y bien pagado (Raphaeli, Roumani y M acKeller, 1984).

\section{Bibliografía}

Ades, A., and R. DI Tella, 1995, National Champions and Corruption: Some Unpleasant Competitiveness Arithmetic. Keble College, 0 xford University.

ALAM, M. S., 1995, «A Theory of Limits on Corruption and Some Applications". Kyklos 48: 419-435.

Andvig, Jens Chr., and Karl O ve M Oene, 1990, «H ow Corruption M ay Corrupt». Journal of Economic Behavior and O rganization 13: 63-76.

BeCKeR, Gary, and George Stigler, 1974, «Law Enforcement, M alfeasance, and
Compensation of Enforcers». Journal of Legal Studies 3: 1-19.

BESLEY, T imothy, and John M CLAREN, 1993, «Taxes and Bribery: The Role of Wage Incentives». Economic Journal 103: 119-41.

Buscaglia, Jr., Edgardo, 1995, «udicial Reform in Latin America: The 0 bstacles Ahead». Journal of Latin America Affairs (fall/winter): 8-13.

CAd 0t, 0., 1987, «Corruption as a Gamble». Journal of Public Economics 33: 223-44. 
CAMPOS, Edward, and Hilton Root, 1996, East Asia's Road to High Growth: An Institutional Perspective. Washington D.C.: Brookings Institution.

Cartier-Bresson, J., 1995, «'ÉEconomie de la Corruption», In D. D ella Porta and Y. M ény, eds., D émocratie et Corruption en Europe. Paris: La D écouverte.

Celarier, M ichelle, 1996, "Stealing the Family Silver». Euromoney (February): 62-66.

Coolidge, Jacqueline, and Susan Rose-ACKermann, 1997, «H igh Level RentSeeking and Corruption in African Regimes: Theory and Cases». Unplished paper.

DEACON, Robert T., 1994, «D eforestation and the Rule of Law in a Cross-Section of Countries». Land Economics 70: 414-30.

D ella PO RTA, D onatella, 1996: «Actors in Corruption: Business Politiciansin Italy». International Social Science Journal (September), 149: 349-64.

De M elo, M artha; Gur O fFer, and O Iga SAn DLeR, 1995, «Pioneers for Profit: St. Petersburg Enrepreneurs in Services». World Bank Economic Review 9: 425-50.

Econ OM ISTI AsSOCIATI, 1994, Eastern Africa-Survey of Foreign Investors, volumes 2 and 3. Report prepared for the World Bank, Washington D.C.

Federal Executive Power of Mexico, 1996: Program for the Modernization of Public Administration 1995-2000. Mexico City.

Find LAY, Ronald, 1991, «s the News Political Economy Relevant to Developing Countries?». In Gerald M. M eier, ed., Politics and Policymaking in Development: Perspectives on the New Political Economy. Washington D.C.: World Bank.

Flatters, Frank, and W. Bentley M acLeod, 1995: «Administrative Corruption and Taxation». International Tax and Public Finance 2: 397-417.

Gam betta, Diego, 1993, TheSiciliam M afia. Cambridge, M ass. H arvard U niversity Press.

Geddes, Barbara, and Artur RiBeIRo Net0, 1992, «nstitutional Sources of Corruption in Brazil». Third World Q uarterly 13: 641-61.

GIGLIOLI, Pier Paolo, 1996, «Political Corruption and the Media: TheTangentopoli Affair». International Social Science Journal (September) 149: 381-94.

Great Britain Audit Commission, 1993, Protecting the Public Purse: Probity in the Public Sector: Combating Fraud and Corruption in Local Government. London: HMSO.

Johnsom, Paul, 1991, The Birth of the Modern: World Society 1815-1830. New York: Harper Collins.

Kaufm An N, D., 1994: «D iminishing Returns to Administrative Controls and the Emergence of the U nofficial Economy: A Framework of Analysis and Applications to Ukranie». Economic Policy (D ecember) 9: 51-69.

Kaufm an N, D aniel, and Aleksander Kaliberda, 1996, «ntegrating the Unofficial Economy into the D ynamics of Post-Socialist Economies: A framework of Analysis and Evidence». In Bartlomej Kam IN SKI, ed., Economic Transition in Russia and the New States of Eurasia. Armonk, N .Y.; M .E. Sharpe.

Keefer, Philip, and Stephen Knack, 1995, «nstitutions and Economic Performance: Cross-C ountry Tests Using Alternative Institutional M easures». Economics and Politics.

KILBY, Christopher, 1994, «Risk M anagement: An Econometric Investigation of Project-Level Factors». Background paper for theAnnual Review of Evaluation Results 1994, Washington, D.C.: World Bank, O perations Evaluation D epartment.

KlitgaARd, Robert, 1985, Controlling Corruption. Berkeley, Calif.: University of California Press.

LuI, Francis, T., 1985, «An Equilibrium Queuing Model of Bribery». Journal of Political Economy 93: 760-81.

M an ION, M elanie, 1996, «Policy Instruments and Political Context: Transforming a Culture of C orruption in $\mathrm{H}$ ong Kong». Paper prepared for the Annual M eeting of the Association for Asian Studies, H onolulu, H awaii.
M anzetTI, Luigi, and Charles Blake, 197, «M arket Reforms and Corruption in Latin America: N ew M eansfor O Id Ways». Review of International Political Economy. M AuRo, Paolo, 1995, «Corruption and Growth». Quarterly Journal of Economics 109: 681-712.

-, Forthcoming, «T he Effects of Corruption on Growth, Investment, and Government Expenditure: A Cross-Country Analysis». In Kimberly Elliott, eds., Corruption in the World Economy. Washington: D.C.: Institute for International Economics.

M ен м Eт, 0 zay, 1994, «Rent-Seeking and Gate-Keeping in Indonesia: A Cultural and Economic Analysis». Labour, Capital and Society 27: 56-89.

M ÉNY, Yves, 1996: «Fin de Siècle Corruption: Change, Crisis and Shifting Values». International Social Science Journal (9) 149: 309-20.

O Lden BuRg, Philip, 1987: «M iddlemen in Third World Corruption: Implications for an Indian Case». World Politics 39: 508-535.

O LSON, M ancur, 1993: «D ictatorship, D emocracy, and D evelopment». American Political Science Review 87: 567-575.

PARK, B.-S., 1995, Political Corruption in N on-Western Democracies: The Case of South Korea Party Politics. Seoul: Kim Dae-Jung Peace Foundation.

PAUL, Sam, 1995, «Evaluating Public Services: A Case Study on Bangalore, India». New Directions for Evaluation (Fall) 67.

Pendergast, William F., 1995, «Foreign Corrupt Practice Act: An 0 verview fo Almost Twenty Years of Foreign Bribery Prosecutions». International Q uarterly 7(2): 187-217.

Phongpaicht, Pasuk, and Sungsidh Piriyarangsan, 1994, Corruption and D emocracy in Thailand. Bangkok: Chulalongkorn University, Faculty of Economics Political Economy Centre.

Po PE, Jeremy, ed. 1996, National Integrity Systems: The TI Source Bok. Berlin: Transparency International.

Pritchett, Lant, and G eeta SeTHI, 1994, «Tariff Revenueand Tariff Reform: Some New Facts». World Bank Economic Review 8(1): 1-16.

Q UAH, Jon S. T., 1993, «C ontrolling Corruption in City-States: A ComparativeStudy of $\mathrm{H}$ ong Kong and Singapore». Paper presented at the conference on «The East Asian M iracle: Economic Growth and Public Policy», Stanford University, Palo Alto.

Raphaeli, N., J. Roum anı, and A. M acKeller, 1984, «Public Sector Management in Bostwana: Lessons in Pragmatism». W orld Bank Staff Working Paper 1709. Washington D.C.

ReEd, Steven R., 1996, «Political Corruption in Japan». International Social Science Journal (9) 149: 395-405.

RodrIK, Dani, 1996, «King Kong M eets Godzilla: The World Bank and The East Asian M iracles. In A. FISH LOW, C. GWIN, S. HAGGARD, D. RODRIK, and R. W ADE, eds., M iracle or Design? Lessons from the East Asian Experience. ODC Policy Essay 11. Washington, D.C.: O verseas D evelopment Council.

Rogers, Glenn, and Sidi Mohammed Iddal, 1996, «N iger: Reduction of Illegal Road Payments». In Governance and the Economy in Africa: Tools for Analysis and Reform of Corruption. College Park, M d.: Center for Institutional Reform and the Informal Sector.

Roodman, David Malin, 1996, Paying the Piper: Subsidies, Politics, and the Environment. Worldwatch Paper 133. Washington D.C.

Rose-Ackerm An, Susan, 1978, Corruption: A Study in Political Economy. New York: Academic Press.

- , 1994, «Reducing Bribery in the Public Sector». In Duc V. Trang, ed., Corruption and D emocracy. Budapest: Institute for Constitutional and Legislative Policy.

- , 1996, «UnaAdministración Reducida Significa una Administración M ás Limpia (Is Leaner Government Cleaner Government?)», N ueva Sociedad (SeptemberOctober): 145: 66-79. 
Rose-ACKerman, Susan, and Andrew Stone, 1996, «The Costs of Corruption for Private Business: Evidence from World Bank Surveys». World Bank, Private Sector Development D epartment, Washington, D.C.

Rowat, M.; W. H. M ALIK, and M. D AKolIAS, eds., 1995, Judicial Reform in Latin America and the Caribbean: Proceedings of a World Bank Conference. World Bank Technical Paper 280. Washington, D.C.

RuzindanA, A., 1995, «Combating Corruption in U ganda». In P. LANGSETH, J. Katarobo, E. Brett, and J. M unene, eds., U ganda: Landmarks in Rebuilding a Nation. Kampala: Fountain Pub.

Shelley, Louise, 1994, «Post-Soviet O rganized Crime». D emokratizatsiya 2: 341358.

SHLEIFER, A., and R. VISHnY, 1993, «Corruption». Quarterly Journal of Economics 108: 599-617.

SKID M ORE, M ax J., 1996, «Promise and Peril in Combating Corruption: Hong Kong's ICAC». Annuals of theAmerican Academy of Political Scienceand Sociology (September) 547: 118-130.

Stasavage, David, 1996, «Corruption and the Mozambican Economy». Paris: OECD Development Centre.

Stella, Peter, 1992, «Tax Farming -A Radical Solution for D eveloping Country Tax Problems?». IM F Working Paper W P/92/70. Washington D.C.: International M onetary Fund.

Stone, Andrew, 1995, «The Climate for Private Sector Development in Pakistan: Results of an Enterprise Survey». Unpublished background paper for Pakistan PSA. Washington, D.C.: World Bank.
VAN RIJCKEGHAM, and Beatrice WedER, 1996, «Corruption and the Rate of Temptation: D o Low Wages in the Civil Service Cause Corruption?». Washington, D.C.: International M onetary Fund.

VINCENT, Jeffrey R., and Clark S. BIN KLEY, «Forest-Based Industrialization: A Dynamic Perspective». In Narendra P. Sharma, ed., M anaging the World's Forests. Dubuque, Iowa: Kendall/Hunt Publishing.

W ADE, R., 1982, «The System of Administrative and Political Corruption: Canal Irrigation in South India». Journal of D evelopment Studies 18: 287-328.

W EBST ER, Leila M ., 1993: TheEmergence of PrivateSector M anufacturing in H ungary. World Bank Technical Paper 229. Washington, D.C.

Webster, Leila, and Joshua Charap, 1993, The Emergence of Private Sector M anufacturing in St. Petersourg. World Bank Technical Paper 228. Washington, D.C.

W El, Shang-Jin, 1997, H ow Taxing is Corruption on International Investors? H arvard University, Kennedy School of Government, Cambridge, Mass.

World Bank, 1993, Adjusment in Africa: Reform, Results, and the Road Ahead. World Bank Policy Research Report. New York: 0 xford University Press.

- 1995, «G hana Country Assistance Review». Report no. 14547. Washington, D.C.

YABRAK, Isil, and LeilaW EBSTER, 1995, «Small and Medium Enterprises in Lebanon: A Survey». World Bank Private Sector Developmet D epartment and Industry and Energy D ivision, M iddle East and North Africa Country D epartment II, Washington, D.C. 
